\title{
Gesprekken met mormoonse vrouwen in Vlaanderen
}

\section{Omgaan met structurele ambivalentie}

\author{
Ellen Decoo QX Chia Longman*
}

\begin{abstract}
Summary
Latter-day Saints (Mormons) living outside the 'Mormon Culture Region' in the Western United States usually form small minorities. As Mormonism upholds conservative gender norms, we investigated how a sample of thirteen Mormon women living in Flanders (Northern part of Belgium) experienced their relation with the Flemish secular-liberal environment. The research used the framework of structural ambivalence to assess how these women cope with conflicting norms on marriage age, male-only priesthood and familial dilemmas. Results show how respondents use arguments and strategies to handle or to avert ambivalence.
\end{abstract}

\section{Inleiding}

Mormoonse vrouwen ... Wat stelt een buitenstaander zich daarbij voor? Literatuur en media hebben het beeld geankerd van een oerconservatieve, patriarchale kerk in de Amerikaanse staat Utah, met op de achtergrond nog hun vroegere polygamie. Verwarring met de leefwereld van de Amish is niet ongebruikelijk. Voor een accurater beeld tonen surveys dat de overwegend mormoonse bevolking in Utah dominant Republikeins stemt en slagwoorden van de 'Christian Right' deelt - 'anti-abortion, anti-feminism, antigovernment \& anti-gay', waarbij vrouwen zich even conservatief als mannen opstellen (Pew Research Center 2014). In Utah zijn zo'n 90\% van de politiek verkozenen mannen, mormoon en Republikein (Davidson 2021). Specifiek wat gendergelijkheid betreft, eindigt Utah jaar na jaar als 'the worst state in the US for women's equality on items such as workplace environment, wage gaps, higher education, health, and political empowerment' (Jacobs 2020). Die uitkomsten worden toegeschreven aan een kerkelijke cultuur die alleen

\footnotetext{
* Ellen Decoo is sociologe en doceert aan het Salt Lake Community College en aan het Westminster College in Salt Lake City, Utah. Zij behaalde een doctoraat over 'Mormon gender roles' aan de Universiteit Gent. Chia Longman is professor in gender studies en directeur van het Centre for Research on Culture and Gender aan de Universiteit Gent.
} 
mannen, via het priesterschap, beslissingsbevoegdheden geeft. Dat trekt door in de maatschappij (Robins 2011). Voor gezinsnormen stelt de kerk het heteroseksueel huwelijk en traditionele genderrollen als fundamentele doctrine, in 1995 bevestigd in een plechtige Proclamatie:

Het gezin is door God ingesteld. Het huwelijk van man en vrouw is van essentieel belang in zijn eeuwige plan (...) Volgens het goddelijk plan behoort de vader zijn gezin met liefde en in rechtschapenheid te presideren. Hij heeft tot taak te voorzien in de levensbehoeften en de bescherming van zijn gezin. De taak van de moeder is op de eerste plaats de zorg voor de kinderen.

Mormoonse kerkleiders blijven die principes benadrukken. Grote gezinnen - zes en meer kinderen - met moeder aan de haard kenmerken de oudere generaties. Hoewel minder dan vroeger weegt dat verwachtingspatroon nog steeds bij jongere mormonen in Utah: zij trouwen vroeg en krijgen meer kinderen dan het nationaal gemiddelde (Heaton \& Jacobson 2015; Uecker 2014).

Officieel de 'Kerk van Jezus Christus van de Heiligen der Laatste Dagen', is de mormoonse kerk dus vooral bekend als een Amerikaanse kerk met haar hoofdzetel en demografische concentratie in Utah en omliggende staten. Het is de zogenaamde 'Mormon Culture Region', een gebied met eigen socioculturele en politieke kenmerken (Phillips \& Cragun 2011). Maar meer dan de helft van de 16,5 miljoen mormonen in de wereld woont thans buiten de Verenigde Staten, overwegend dun gespreid als kleine minderheden. Dat is het resultaat van zendingswerk verricht door jongvolwassen kerkleden die twee jaar lang voltijds hun boodschap uitdragen (de jonge vrouwen 18 maanden). In nagenoeg alle landen van de wereld vind je dus nu mormoonse gemeenten of parochies - in mormoons taalgebruik 'wijken' genoemd. Vaak vormen zij een minuscule minderheid in een overwegend liberale, seculiere maatschappij. Toch isoleren ze zich niet zoals bijvoorbeeld strikt orthodoxe joden. Mormonen nemen deel aan het normale maatschappelijk leven. Daar gelden echter normen en gewoonten van de landstreek, bijvoorbeeld met betrekking tot huwelijksleeftijd, gezinsgrootte, tewerkstelling voor vrouwen, enz. Zo ontstaat een spanningsveld tussen de 'lokale' waarden en gewoonten en de kerkelijke richtlijnen die de sfeer in Utah bepalen. Dat spanningsveld geldt ook voor de Lage Landen (Van Beek 2005; Van Beek, Decoo \& Decoo 2020).

Eind 2020 telde de kerk 24 wijken in Nederland en 4 in Vlaanderen, een per grotere stad, met een totaal van ongeveer 10.000 leden. Daarvan nemen zo'n 25 à 30\% actief deel aan het kerkelijk leven, wat gemiddeld een honderdtal praktiserende leden per wijk oplevert. Dat kerkelijk leven bestaat uit een 
zondagse ochtenddienst met bediening van het avondmaal (stukjes brood en bekertjes water), toespraken en zondagschoollessen, in een rustige protestantse traditie. Kerkleden zijn sterk betrokken in programma's voor de jeugd, in zendingswerk, in familiegeschiedenis en in maatschappelijk dienstbetoon. Een wijk draait volledig op vrijwilligers die voor tijdelijke taken in de sterk vertakte organisatie aangesteld worden. De druk op participatie is groot. Hoewel conservatief op het vlak van moraal, is de kerk wel progressief in haar nadruk op hoger onderwijs en maatschappelijk succes. Voor meer gegevens over organisatie en leer verwijzen we naar een vorige bijdrage over het mormonisme in Religie \& Samenleving (Decoo \& Decoo 2019).

Met op de achtergrond het beeld van het gender-ongelijke, conservatieve mormonisme in Utah en de traditionele genderrollen die kerkleiders blijven benadrukken, formuleren wij de vraag: hoe beleven mormoonse vrouwen in Vlaanderen aspecten van genderrollen en hun relatie met de niet-mormoonse samenleving? Ons onderzoek situeert zich in het kader van studies over vrouwen in conservatieve religies (Avishai 2008; 2016; Burke 2012). In deze bijdrage verduidelijken we eerst het theoretisch kader van ons onderzoek en de gevolgde methode. Vervolgens bespreken we de bevindingen voor enkele topics - huwelijksnormen, mannelijk priesterschapsgezag en dilemma's in het gezin. Zo komen we tot een besluit met relevantie voor gelijkaardige benaderingen van religieuze minderheden.

\section{Theoretisch kader: structurele ambivalentie}

Ons onderzoek gebruikt het concept van structurele ambivalentie (SA). ${ }^{1}$ Ambivalentie in de zin van tegenstrijdige gevoelens hoort tot de menselijke natuur, met de liefde-haat relatie als bekend voorbeeld. Wanneer overkoepelende structuren die tegenstrijdigheden voeden, spreken sociologen van SA. Voorbeelden zijn legio. Ouders zitten vaak geprangd tussen gezinsplichten en beroepseisen. Managers balanceren tussen opvoering van productiviteit en veiligheidsvoorschriften. Eeuwen geleden diende Antigone al te kiezen tussen seculiere of religieuze gehoorzaamheid.

Voor de theorievorming van SA wordt meestal verwezen naar Merton en Barber. Hun raamwerk gaat ervan uit dat mensen op de intersectie van verschillende structurele entiteiten, zoals familie, werk of religie, vaak tegenstrijdige normen, waarden of verwachtingen tegenkomen. Zij kunnen dan verschillende rollen spelen volgens de situatie: 'Potentially conflicting norms are built into the social definition of roles that provide for normatively 
acceptable alternations of behavior as the state of a social relation changes' (Merton \& Barber 1963, 105). Steele \& Helmuth (2019, 423) definiëren SA as 'the attitudinal outcome that arises when individuals are situated at the intersections of multiple socio-structural institutions that convey conflicting normative messages'. Om de tegenstrijdigheden te verminderen, te ontwijken of op te lossen, hanteren individuen vaak argumenten en strategieën. In die zin zijn persoonlijke reacties op SA ook de uiting van vrije wil.

Het concept vond vooral toepassingen in de studie van relaties rond familie en maatschappij (Connidis \& McMullin 2002; Järvinen \& Luckow 2020). Maar ook religie bleek bij uitstek een domein dat SA kan uitlokken. Sommige religies vereisen overtuigingen en belevingsvormen die aanschuren tegen wat in de omliggende maatschappij gangbaar is. Om spanningen te vermijden passen sommige gelovigen hun rollen aan volgens de context. Anderen doen dit niet, isoleren zich of komen mogelijk in conflict met de buitenwereld. De dynamiek van SA kan gelovigen ook van attitude doen veranderen, bijvoorbeeld ten overstaan van lgbt's (Bean \& Martinez 2014; Steele \& Helmuth 2019). Soms is SA een ingewikkeld en diep ingeworteld stramien zoals bij orthodoxe joden in Israël (Finkelman 2014; Kopelowitz 2001). Hoe moslims hun identiteit bevestigen of aanpassen in een andere culturele context is evident studiemateriaal voor SA (Burchardt, Griera \& García-Romeral 2015; Khan 2002). Complexer wordt het wanneer de invloeden van drie entiteiten meespelen, zoals gender, religie en maatschappij (Bulanda 2011). Ten slotte is bekering tot een religie meestal een omvattende oefening in SA wanneer de bekeerling andere sociale rollen opneemt en nieuwe normen vroegere verdringen (Gooren 2010; Van Nieuwkerk 2014).

Voor onze studie van mormoonse vrouwen in Vlaanderen is het concept van SA evident relevant. Zij laveren tussen structuren met tegenstrijdige normen. De strakke patriarchale en heteronormatieve genderrollen die de kerk voorhoudt passen niet bij de principiële gendergelijkheid in de maatschappij. Vroeg trouwen om een groot gezin te stichten is niet gebruikelijk. Welke argumenten en strategieën hanteren vrouwen om met die SA om te gaan?

\section{Methode}

Dertien mormoonse vrouwen woonachtig in Vlaanderen namen deel aan een kwalitatief onderzoeksproject middels individuele semigestructureerde interviews. Een vrouwelijk kerklid dat vanuit haar jarenlange functies in de kerk veel mensen kende hielp als 'key informant' een doelgerichte sample samen 
te stellen van een dertigtal kandidaten: praktiserende mormoonse vrouwen met veel kerkervaring. Daaruit werd een kleinere groep, qua aantal doenbaar voor de interviews, geselecteerd met het oog op maximale variatie op een aantal factoren: leeftijd (van 28 tot 93), burgerlijke staat ( 2 nooit gehuwd, 8 gehuwd, 3 gescheiden), aard van het lidmaatschap (7 bekeerlingen, 6 opgegroeid binnen een mormoons gezin), gezinsgrootte (van o tot 5 kinderen), tewerkgesteld of niet (er kon echter geen respondent gevonden worden zonder beroep), onderwijsniveau (1 middelbaar onderwijs, 5 bachelors, 5 masters en $2 \mathrm{PhD}$ ), religieuze attitude (van conservatief tot meer liberaal) en kerkelijke inzet (van heel geëngageerd tot iets minder). Drie respondenten hadden een Nederlandse achtergrond en twee een Sub-Saharaanse, maar ze woonden al vele jaren in Vlaanderen. Die variatie verzekerde uiteenlopende achtergronden maar het aantal respondenten was uiteraard te klein voor een eigenlijke factoriële weging zoals in kwantitatief onderzoek.

De interviews werden afgenomen door Ellen Decoo, vanuit een positie als insider/outsider. Als insider kende zij bijna alle respondenten erg goed vanuit haar eigen mormoonse jeugdjaren in Vlaanderen, maar was daarna naar Utah geëmigreerd. Via sociale media en jaarlijkse bezoeken bleef ze wel goed op de hoogte van de kerkleden in Vlaanderen. Elk interview vond dan ook plaats in de sfeer van een blij weerzien en van openhartigheid. Wanneer door een outsider ondervraagd, zullen leden van een religieuze minderheid, zeker als die al kampt met een imago van marginaliteit, eerder embelliserend of defensief antwoorden. Bij mormonen geldt dat makkelijk, zoals ze het gewend zijn door hun zendingswerk, publicaties en websites die enkel de mooie kanten tonen. Die intentionaliteit speelde hier niet mee. Door haar insider-kennis kon de interviewer de compacte informatie (inclusief innuendo's, afkortingen en jargon) ook meteen goed vatten en in de juiste context plaatsen. Tegelijkertijd was voor de respondenten de interviewer ook een wetenschappelijke outsider die na het onderzoek naar de VS zou terugkeren en de openhartige gegevens onder voorwaarde van anonimiteit zou verwerken. De gedetailleerde vragenlijst was zo gevarieerd opgesteld, op basis van literatuurstudie en oplijsting van topics, dat het de eigen kring van de insider ver overtrof. Tijdens het interview beperkte de insider zich tot bevestigend en aanmoedigend luisteren en knikken, zonder zelf ooit tussen te komen om zo elke bias of beïnvloeding van haar kant te vermijden. De gesprekken werden opgenomen (gemiddeld bijna twee uur per respondent), uitgeschreven en geanalyseerd op voorkomens van SA. Argumenten werden gecollationeerd om overkoepelende strategieën te identificeren vanuit de mogelijke spanningen tussen de structuren van gender, geloof, kerk, maatschappij en gezin. 
Het hoofddoel van het onderzoek betrof de perceptie van genderrollen maar de uitgebreide vragenlijst verbreedde dit tot meerdere religieuze en maatschappelijke aspecten. Naast directe vragen bevatte de vragenlijst ook situaties (vignetten) waar de respondent expliciet met SA geconfronteerd werd.

\section{Bevindingen en bespreking}

Voor een volledig verslag van het onderzoek verwijzen we naar Decoo (2021). Hier kozen we voor drie representatieve topics met verschillende accenten: SA in de maatschappelijke sfeer rond huwelijksnormen, SA in de relatie met het exclusief mannelijk priesterschap en SA in de familiale sfeer rond religieuze normen. Nagenoeg alle soorten argumenten en strategieën die ook in andere topics aan bod kwamen, zijn in de hier besproken voorbeelden te vinden.

In navolgende citaties zijn de namen van de respondenten gewijzigd. We vermijden de systematische melding van factoren zoals leeftijd, beroep of onderwijsniveau bij elke respondent om zo de anonimiteit zoveel mogelijk te beschermen. Waar nodig gebruiken we geijkte mormoonse termen zoals priesterschapsdrager of jongevrouwenpresidente.

\section{Vroeg trouwen? Nee, en wel hierom ...}

In de VS trouwen mormonen jong, gemiddeld op 22-jarige leeftijd, tien jaar eerder dan andere Amerikanen op hun $32^{\text {ste }}$ (Riess 2019, 75). In België en Nederland is dit voor de algemene bevolking eveneens gemiddeld 32 . Mormoonse kerkleiders dringen aan op het niet uitstellen van het huwelijk, zowel om demografische redenen als om voorhuwelijkse seksuele relaties tegen te gaan (bijvoorbeeld Monson 2011; Oaks 2018). Oproepen en vermaningen daartoe doen ze op algemene conferenties en in het wereldwijd verspreide kerkelijk maandblad dat ook in het Nederlands verschijnt. Gehoorzaamheid aan kerkleiders is een sterk benadrukt principe in het mormonisme. Aan de respondenten werd deze vignette voorgelegd:

Een jongeman beëindigt zijn tweejarige zending. Hij is 20 jaar oud. Bij het laatste interview zegt de Amerikaanse zendingspresident hem dat hij niet moet wachten om een meisje te vinden en in de tempel te trouwen. Hij komt terug thuis en maakt al snel kennis met een meisje van zijn leeftijd. Het klikt wel, maar als hij 
na een zestal maanden voorstelt te trouwen, zegt het meisje dat zij liever nog twee tot drie jaar wil wachten tot ze beiden afgestudeerd zijn. De jongen wijst erop dat kerkleiders erop aandringen om het huwelijk niet uit te stellen. Wat denk je van dit dilemma?

De ambivalentie is evident: kiezen tussen kerkelijke of lokale maatschappelijke normen. Geen van de dertien respondenten koos voor de kerkelijke norm. Om met de daaruit vloeiende SA om te gaan gebruikten ze verschillende argumenten en strategieën.

\section{Op negatieve gevolgen wijzen}

Verschillende respondenten argumenteerden hun afwijzing van de kerkelijke raad door te wijzen op mislukte huwelijken tussen jonge mormoonse stellen. Daphne verwees boos naar hen als "mensen die dachten "ik kan dat" en die eindigden met niets, geen diploma's, geen huwelijk meer, maar nog steeds met kleine kinderen.' Irma merkte evenzeer op:

Kinderen, studie, werk, het lijkt mij een enorme belasting voor een huwelijk. Ik heb het hier gezien: velen hebben dat advies opgevolgd [om jong te trouwen], ze krijgen een kind en gaan dan scheiden.

Zonder de kerkleiders openlijk te bekritiseren, impliceerden deze respondenten het onverstandige van de richtlijn door op negatieve gevolgen te wijzen: dat rechtvaardigde het niet hoeven te gehoorzamen.

\section{De draagwijdte van de richtlijn inperken}

De meeste respondenten losten de SA (ook) op door te wijzen op maatschappelijke verschillen met Utah, implicerend dat de Amerikaanse kerkautoriteiten zich alleen richten op hun eigen geografische situatie. Zo verklaarde Irma dat men in Utah jong kon trouwen omdat 'het systeem daar' voorzieningen heeft voor jonge getrouwde studenten die kunnen genieten van 'universitaire huisvesting met banen en al de rest' of die 'in de basement van hun ouders kunnen wonen terwijl vader hun studie betaalt'. Daphne sprak een soortgelijk argument uit: 'We zijn niet in Utah waar studie en werk beter kunnen worden gecombineerd dan hier.' Lisette: 'Hier bij ons kun je, als je nog studeert, nog niet trouwen. Dat is heel anders dan in Amerika. Dat vind ik een groot cultuurverschil.' Ze vertelde ook dat toen haar 21-jarige zoon thuiskwam van zijn zending - met de opdracht om snel te trouwen - ze tegen hem zei: 'Zorg er gewoon voor dat je eerst je studie afmaakt.' De man was nu tegen de dertig en 
nog ongehuwd. Dit cultuurverschil met Utah gebruikten respondenten ook om andere gevallen van SA te ontmijnen, zoals tewerkstelling voor moeders met nog jonge kinderen thuis of de beperking van het aantal kinderen.

\section{God en geloof aanroepen}

Enkele respondenten pakten de SA aan door wel gehoorzaam in te stemmen met de kerkelijke richtlijn, maar hun geloof aan te grijpen als strategie om de richtlijn te omzeilen. Tonja:

Mijn dochter zit nog op de universiteit en haar vriend is een teruggekeerde zendeling en zit nu ook nog op school. Ik kan begrijpen dat ze willen wachten. Dus ik heb zoiets van: 'Ik vertrouw jou, meisje, en ik vertrouw die man.' Onze Hemelse Vader ziet ze, en hij weet wat het beste voor ze is, en wat ze ook doen, het zal het beste voor ze zijn.

Door te verwijzen naar Gods welwillendheid ontweek Tonja de tegenstrijdigheid: wat het jonge paar ook besluit, het heeft goddelijke goedkeuring en kan dus niet in strijd zijn met kerkelijke richtlijnen. Ook Vera koos voor een religieuze invalshoek door zich te beroepen op de mormoonse leer dat elk individueel lid via gebed recht heeft op 'persoonlijke openbaring' - een geestelijk gevoel van bevestiging - om de juiste beslissingen te nemen. Dus kon ze het zo stellen vanuit het standpunt van het meisje dat zich uit gehoorzaamheid verplicht zou voelen tot een vroeg huwelijk:

Ik begrijp wat onze profeet zegt, wacht niet langer en ga ervoor, en dan denk ik dat het nodig is om hier met geloof te werken en gebed. Als ze zeggen dat je persoonlijke openbaring krijgt, nou, dan moet dat meisje er zich goed bij voelen, en als ze 'nee' zegt, dan is het 'nee'.

\section{Maar seks blijft een probleem}

De sterkste ambivalentie, omdat onoplosbaar, werd verwoord in de spanning tussen maatschappelijke normen en de religieuze wet van kuisheid. De 93-jarige Didi beoordeelde het standpunt van de kerk als 'totaal verkeerd'. Ze was van mening dat het jonge paar het huwelijk moest uitstellen zolang ze student zijn om 'veel problemen en veel ellende' te voorkomen. Maar ze begreep het dilemma om zich te onthouden van seks voor het huwelijk: 'Een aantal jaren wachten zonder ... dat is moeilijk, dat is onmogelijk.' Ook Daphne was het niet eens met de nadruk op jong trouwen, en was evenzeer in strijd: 
'Het is moeilijk om rein te blijven als je verliefd bent.' Saskia sprak dezelfde zorg uit:

Ik denk dat het veel verdriet zou voorkomen als ze niet zo snel zouden trouwen. Maar er is die wet van kuisheid. Dat verhoogt de druk - 'moeten we niet trouwen?' Die gevoelens, die hunkeringen, die heb je, maar dat mag je niet.

Geen van deze respondenten zei verder dat seks voor het huwelijk of samenwonen in dergelijke omstandigheden acceptabel zou zijn. Aan zo'n heilig principe als de wet van kuisheid wilden ze openlijk niet raken. Anna omzeilde het seksprobleem door te stellen dat jong trouwen wel mogelijk moet zijn 'als het hun keuze is, maar ik hoop dat ze niet snel kinderen zullen krijgen.' Door dat onderscheid te maken vond ze evenwicht tussen de kerkelijke richtlijn en maatschappelijke voorzichtigheid, maar ontliep zo wel de onderliggende kerkelijke verwachting voor snelle nakomelingen.

\section{Priesterschap: een mannenzaak, maar dat is oké}

Vanaf de leeftijd van twaalf jaar wordt aan alle mormoonse jongens, voor zover ze actief in de kerk zijn, door handoplegging het priesterschap 'verleend'. Volgens de leeftijd worden ze dan 'geordend' tot verschillende ambten. In het lagere of Aäronische priesterschap worden ze diaken in het jaar dat ze 12 worden, leraar bij 14 en priester bij 16. Op 18-jarige leeftijd worden ze dan 'ouderling' in het hogere of Melchizedekse priesterschap. Het priesterschap is nodig voor de verordeningen (zoals dopen, een zegen geven, zieken zalven, anderen ordenen, het zondagse avondmaal inzegenen). In het gezin is de vader de priesterschapsdrager die 'presideert' en gewoonlijk zijn eigen kinderen doopt en zijn zoons ordent tot de verschillende ambten in het priesterschap. In de kerkelijke hiërarchie kunnen alleen priesterschapsdragers leiderschapsfuncties vervullen, van de 'profeet' aan de top tot de jonge 'diakenenquorumpresident' in een wijk. Voor de hele wijk zelf is de bisschop de leidinggevende priesterschapsdrager. Hij wordt hiervoor vanuit een hoger hiërarchisch niveau 'geroepen' om dit een aantal jaren vrijwillig en kosteloos te doen, naast zijn gewoon werk in de maatschappij. Samen met zijn twee mannelijke raadgevers vormt hij de bisschap. Zij bepalen wie de vele andere functies in de wijk vervullen. Via een persoonlijk interview worden mensen zo 'geroepen' tot een taak of ervan 'ontheven'. 
Het potentieel voor SA is ook hier evident. Terwijl in de maatschappij principiële gendergelijkheid geldt, krijgen in de mormoonse kerk meisjes en vrouwen geen priesterschap, kunnen ze geen verordeningen uitvoeren en zijn ze uitgesloten van institutionele beslissingsbevoegdheid. In de VS tracht een kleine minderheid van mormoonse feministen al jaren om die toestand bij te sturen, met de beweging 'Ordain women' als de meest vocale. In ons onderzoek peilden verschillende vragen dan ook naar de relatie van de vrouw met het priesterschap. Bewust van het feit dat voor de buitenwereld de kerk als patriarchaal en vrouw-discriminerend overkomt, begrepen alle respondenten het onderwerp meteen in het licht van gendergelijkheid. Maar terwijl voor de topic van 'vroeg trouwen' de respondenten de maatschappelijk kaart in het nadeel van de kerk trokken, gebeurde hier het omgekeerde: overwegend verdedigden de respondenten de kerkelijke situatie. Ze gebruikten er verschillende argumenten en strategieën voor.

\section{Het positief gedragseffect op mannen onderstrepen}

Een vraag luidde: Hoe voel je erover dat enkel mannen het priesterschap krijgen? De meeste respondenten vonden dat prima, zowel in de familiale als in de institutionele context, met als argument het effect op hun gedrag. Veel toespraken en lessen in de kerk gaan immers over de plichten van priesterschapsdragers als dienstverleners. Mormoonse schriftuur stelt dat het priesterschap 'alleen door overreding, door lankmoedigheid, door mildheid en zachtmoedigheid, en door ongeveinsde liefde' kan gebruikt worden (Leer en Verbonden 121:41). Renée zag het dan ook in dat perspectief van een leerschool:

Ik denk dat er eigenlijk niets beters is dan een man te hebben die het priesterschap draagt. Ik maak er soms grapjes over en zeg: 'Mannen krijgen het priesterschap omdat ze moeten leren wat vrouwen al heel lang weten.'

Vera noemde het priesterschap 'een zegen voor het gezin'. Didi: 'Ik zeg wel eens tegen mijn man: Jij bent priester, je hebt het recht om in de naam van God te handelen, dat is iets heel heiligs.' Lisette:

Jongens krijgen het priesterschap als ze 12 jaar oud zijn, en de meisjes krijgen niets. Maar is dat zo? De mannen zien het als een verantwoordelijkheid die ze moeten dragen. Ik voel me gezegend met twee priesterschapsdragers in mijn gezin [man en zoon]. Ik heb er geen probleem mee dat het alleen aan mannen wordt gegeven. 
Uit onderzoek blijkt die houding algemeen in de wereld. De overgrote meerderheid van mormoonse vrouwen vraagt niet om het priesterschap, essentieel vanuit een besef dat het priesterschap echtgenoten aanzet tot trouw en dienstbaarheid (Lipka 2013). Dat geldt evenzo in Europese landen (DecooVanwelkenhuysen 2016).

Ook in de institutionele context van de kerk, waar priesterschapsdragers instaan voor steun aan anderen, wordt dit gewaardeerd. Sigrid:

Ik vind het geweldig dat er een macht uit de hemel is die onze mannen nederig kunnen gebruiken om anderen te dienen. Ik hou daarvan. Het is net als toen onze huisonderwijzer me een heel mooie zegen gaf die echt bij me paste. Als een man nederig zijn priesterschap wil gebruiken om anderen te dienen, is dat heel bijzonder. Ik heb veel respect voor dat priesterschap.

Stella zag het zelfs als een vorm van empowerment voor vrouwen wanneer een man zich door zijn priesterschap dienend opstelt door te komen helpen of een zegen door handoplegging te geven:

Ik kan aan meerdere mannen en meerdere situaties denken, waar die mij echt wel hebben ondersteund. Als mannen echt naar hun priesterschap leven, dan is dat gewoon ongelofelijk. En dan voel je je ook enorm gesteund als vrouw. Dan voel je je echt empowered als een man dat deftig doet.

\section{Op voldoende vrouwelijke impact wijzen}

Een andere vraag luidde: Zouden vrouwen meer beslissingsbevoegdheid moeten krijgen? Hier verschoof de focus van het priesterschap als religieuze kracht en als dienende functie naar het priesterschap als de besturende bevoegdheid in de organisatie. Op een enkele uitzondering na, vonden de respondenten meer bevoegdheid voor vrouwen niet nodig omdat ze, volgens hen, al voldoende impact hebben. Vrouwen nemen inderdaad een beduidende plaats in het lokaal kerkelijk leven in: ook zij bidden en geven toespraken in de diensten, onderwijzen in de zondagschool, beheren hun 'hulporganisaties' de ZHV (zustershulpvereniging voor volwassen vrouwen), de Jonge Vrouwen (voor meisjes van 12 tot 17) en het Jeugdwerk (voor kinderen onder 12). De vrouwelijke presidenten van deze organisaties hebben, net zoals de bisschop, twee vrouwelijke raadgeefsters in hun 'presidium' en tal van anderen in allerlei functies. Zij vergaderen geregeld met de mannelijke leiders in een 'wijkraad'. Daarnaast zijn er nog evenwaardige functies voor zowel mannen als vrouwen, 
in zondagsschool, welzijnszorg, programma's voor alleenstaanden, public relations, familiegeschiedenis, zendingswerk, muziek, mediatheek. Didi:

Vrouwen zijn ZHV-presidente, jongevrouwenpresidente, jeugdwerkpresidente. En als we met priesterschapsleiders vergaderen, wordt er naar de vrouwen geluisterd. Ze zijn betrokken en wat we zeggen wordt geaccepteerd. Toch zou ik het vreemd vinden als er een vrouw in de bisschap zou zitten. Maar ik voel me niet minder. En als ik een mening heb, zeg ik dat tegen de bisschop.

Lisette, met jarenlange ervaring als ZHV-presidente in de wijk, aarzelde niet om te stellen:

Ik denk dat een ZHV-presidente, vooral op wijkniveau, een zeer belangrijke leidinggevende positie heeft. Want uiteindelijk werkt de bisschop met haar samen. We hebben het priesterschap niet, we staan altijd onder leiding van het priesterschap. Maar ik vind wel dat er echt rekening wordt gehouden met vrouwen. Ik denk echt dat ZHV-presidentes de kerk soms leiden. Alleen is het niet zo zichtbaar, ze zitten niet vooraan. Maar ik denk dat achter de schermen de vrouwen de baas zijn. Vrouwen doen veel werk in de kerk. Ik was uitgeput na vijf jaar als ZHV-presidente. Dat kost veel energie. Ik denk dat veel vrouwen zeer sterke persoonlijkheden hebben en heel vaak de wijk runnen.

Daphne zag vrouwelijk leiderschap als 'onderdeel van de bisschap', maar maakte de impact afhankelijk van de houding van mannen: 'In een goede wijk, met goed priesterschapsleiderschap, zijn de ZHV-presidente, de jongevrouwenpresidente en de jeugdwerkpresidente deel van de bisschap. Elk heeft zijn verantwoordelijkheid. Een goede wijkraad omvat elke organisatie.' Enkele respondenten verwezen wel naar enkele slechte ervaringen met de een of andere Amerikaanse leider uit Utah die niet gewend was aan de volmondigheid van Vlaamse vrouwen.

\section{Op termijn op meer impact en gelijkheid rekenen}

Verschillende respondenten namen standpunten in die de SA konden relativeren op een tijdslijn van veranderingen. Zo werd opgemerkt dat de impact van vrouwen op het lokale kerkbestuur de voorbije decennia was toegenomen. De algemene kerkleiding heeft inderdaad, onder feministische druk, in de loop der jaren wijzigingen doorgevoerd die vrouwen meer zichtbaarheid en inbreng geven op alle hiërarchische echelons. Dit gebeurde onder meer door 
de betrokkenheid van vrouwen in raadsvergaderingen uit te breiden en te formaliseren. Vera:

In de meer dan twintig jaar dat ik lid ben van de kerk is het ook wel geëvolueerd. In het begin had ik het gevoel dat we als vrouwen iets minder belangrijk waren. Maar nu, in de vergaderingen waarin ik zit, heb ik wel het gevoel — ook niet bij iedereen, elke leider is anders - dat we veel meer gehoord worden en ook veel meer betrokken worden.

Drie respondenten waren kritischer over die tijdslijn. Ze erkenden dat vrouwen in alles sterk betrokken zijn, maar dat uiteindelijk de priesterschapsleiders de belangrijke beslissingen nemen. Voor Irma 'leeft de kerk nog in de jaren vijftig voor heel wat zaken en draait de kerk, als een olietanker, vreselijk traag'. Renée merkte op: 'De vrouw krijgt bij ons, in theorie althans volgens de leer, een evenwaardige plaats naast de man. Ze willen het doen lijken dat het zo is. Maar in de praktijk zijn we er nog niet helemaal.' Saskia drukte de relativering zo uit dat het probleem meer individueel dan structureel geduid kon worden:

Het hangt er natuurlijk ook vanaf wie dat er op moment bisschop is in de wijk. Bij de ene kan je veel dingen aankaarten en wordt er ook naar geluisterd en iets mee gedaan. Maar ik heb vaak het gevoel dat onze rol zich beperkt tot het mogen aangeven van dingen, maar de eindverantwoordelijkheid ligt bij de mannen en de priesterschapsdragers. Maar knopen kunnen doorhakken zonder dat je expliciet toestemming moet hebben van een priesterschapsdrager, dat op zich zou veel vrouwen een fijn gevoel geven.

\section{Vrouwelijk priesterschapsgezag claimen}

Een heel andere manier om het gevoel van genderongelijkheid over het priesterschap te ontwijken is dat priesterschap te claimen. Enkele respondenten trokken die kaart vanuit eigen invalshoeken. Saskia, een rationeel ingestelde Millennial, verwoordde het zo:

Voor mij is het priesterschap gewoon een jasje dat een man aantrekt, de autoriteit die iemand krijgt, omdat dat zo bepaald is door de kerk. Officieel is dat de macht om je in de naam van God in dienst te zetten van anderen. In dat opzicht heeft een vrouw evenveel priesterschap, maar wordt dat gewoon niet zo benoemd. Het is gewoon een rol die je op je neemt. 
Judith, een alleenstaande moeder, verwoordde haar claim op priesterschapsgezag met meer gelovige intensiteit:

Als ik thuis, ik heb het meegemaakt, als ik een kind heb dat ziek is, ik draag niet priesterschap in de letterlijke zin dat ik niet een man ben met het priesterschap, maar ik ben wel begiftigd met macht, ook van God. Dus als ik mijn kind in mijn armen neem vanuit mijn diepe liefde, vanuit die macht en een gebed doe, voor mij is dat even sterk dan wat de priester zou doen met handoplegging.

Vervolgens vertelde ze heel levendig hoe op een dag een buurvrouw aan haar deur kwam en schreeuwde dat haar baby niet meer ademde. Ze rende met de vrouw naar haar flat, nam de baby in haar armen en legde haar hand op het hartje. 'En het kind begon te ademen! Ik beweer niets, maar dat is wat er is gebeurd.' Ze eindigde het verhaal met een langzaam benadrukte zin: 'Het priesterschap is de kracht van God!'

\section{Naar de tempel en de eeuwigheid verwijzen voor deelname in het priesterschap}

In de beleving van het mormonisme neemt de tempel een heel aparte plaats in. Het is een groot en statig gebouw, heel anders dan de gewone functionele kerkgebouwen (Nederland telt er een in Zoetermeer en is er onlangs een aangekondigd voor Brussel). Slechts leden die waardig zijn bevonden, na een interview over hun geloof en toewijding, mogen er deelnemen aan een plechtigheid die de eeuwige vooruitgang van de mens verbeeldt, vanaf de schepping tot het betreden van het celestiale koninkrijk. Mannen en vrouwen participeren er op gelijke voet. De kerk beschouwt de ceremonie zo heilig dat ze er slechts karige beschrijvingen van geeft, waaronder wel de melding dat het concept van priesters en priesteressen er deel van is. Meerdere respondenten verwezen dan ook naar dat tempelperspectief om hun relatie met het priesterschap te duiden. Sommigen zagen het als een reeds bestaand voorrecht, anderen als een toekomstig. Judith zag het als reeds bestaand:

Het is moeilijk om te verwoorden, maar ik ben het er niet mee eens dat sommige zusters menen dat wij als vrouwen ver van het priesterschap staan. Ik was vorige week nog in de de tempel. Ik nam deel aan de voorverordeningen, en ik zeg: Maar kijk, alles draait rond het priesterschap en de macht van God hier op aarde. Die zusters die mij hier met de verordeningen helpen, die hebben die macht van God, want anders mochten ze dit heilige werk niet doen. 
Anderen zagen het priesterschap in de toekomst. Lisette: 'Ik vind het niet erg dat we het priesterschap nu niet hebben omdat er in de tempel een belofte is gedaan dat we later priesteressen zullen worden.' Nog anderen schuifelden tussen de perspectieven. Lucia maakte een onderscheid tussen een gedeeltelijke, tijdelijke taak en het volledige priesterschap: 'Als vrouw zijn we immers niet helemaal zonder priesterschap, want in de tempel vervullen we ook een priesterschapstaak. Ik geloof dat we het later ook zullen hebben.' Op dezelfde manier gebruikte Didi de uitdrukkingen 'deel hebben aan het priesterschap' versus ‘het priesterschap hebben' om de dynamiek uit te drukken: 'Ik voel me niet benadeeld omdat ik als vrouw deel heb aan dat priesterschap en later ook het priesterschap zal hebben. Dat leer je in de tempel. Daar zul je priesters en priesteressen zien.' Daphne, die een 'tempelzending' vervulde (tot een jaar of langer in de tempel dienen), zei: 'Toen ik als tempelzendelinge werd aangesteld, zei de raadgever in het tempelpresidium mij letterlijk: 'Dit is de enige plaats waar $\mathrm{u}$ als vrouw het priesterschap kunt bezitten'.

Al bij al blijkt vrouwelijk priesterschap in het tempelperspectief redelijk ambigu en ook beperkt tot die locatie. Toch gaf het deze respondenten een uitweg op de SA dat hun uitsluiting van het priesterschap een vorm van genderongelijkheid zou zijn.

\section{Religieus dilemma: 'Gebruik nu toch even je gezond verstand.'}

Net zoals in andere religies die strikte gedragscodes kennen, vertonen mormonen een gamma van attitudes, van extreme nauwgezetheid tot conveniënte soepelheid. Schriftuurlijke letterlijkheid en stipte gehoorzaamheid typeren de strak conservatieve houding. Liberalen relativeren. Op het microniveau concretiseert de tegenstelling zich vaak rond twee geboden: het 'Woord van Wijsheid' en de sabbatheiliging. Het 'Woord van Wijsheid' is een gezondheidswet uit 1833 die alcohol, tabak en 'hete dranken' verbiedt. Hete dranken worden nu begrepen als koffie en tee, met cafeïne als de boosdoener. Strikte leden verbannen cola, gedecafeïneerde koffie of het koken met wijn. Cola thuis in de koelkast kenmerkt liberaliteit. Voor de sabbatheiliging (op zondag) sluiten conservatieven alle vormen van sport, winkelen, deelname aan evenementen of restaurantbezoek uit. Liberalen kijken minder nauw. In de kerk, tijdens de zondagdienst en de lessen, overweegt conservatisme. Liberalen zullen er dus niet vertellen dat ze straks op restaurant gaan. Voor hen geldt SA tussen kerk en familiale of persoonlijke gewoonten. Kinderen uit een meer liberaal gezin horen in hun kerklesjes strakke normen, zeker uit de mond van een 
conservatieve leerkracht, terwijl ze weten dat ze het thuis niet zo strikt volgen. SA wordt deel van hun leefpatroon.

Met betrekking tot gender kan het conservatief-liberaal contrast voor familiale spanningen zorgen wanneer een van de huwelijkspartners naar de ene of de andere attitude (sterk) overhelt. Volgens de kerkelijke leer is het de taak van de man om te 'presideren' in het gezin ook al dient hij dat 'met liefde en in rechtschapenheid' te doen. Hij is immers diegene die het priesterschap draagt. Hoe zal een conservatief-ingestelde vrouw met SA omgaan als haar man voor een belangrijk bedrijfsweekend met partner is uitgenodigd en hij daar geen graten in ziet, zeker in het belang van zijn carrière? Of, liberaalingesteld, hoe zal zij argumenteren als haar man problemen maakt over een zomerjurkje met ontblote schouders voor hun twaalfjarige dochter om zo 's zondags naar de kerk te gaan? Een van de voorgelegde vignetten luidde:

In een gezin stelt zich het volgende probleem. Myriam, een van de kinderen, 9 jaar oud, wordt voor een verjaardagsfeestje bij niet-leden van de kerk uitgenodigd, maar het is op een zondagnamiddag. De ouders bespreken het eerst onder elkaar. De moeder vindt dat dit wel moet kunnen want haar dochtertje heeft het al moeilijk om vrienden op school te maken en dit is een mooie kans om zich geïntegreerd te voelen. De vader vindt dat het niet kan, want volgens hem moeten de kinderen leren wat het betekent de sabbat te eren. Hoe zou jij hierover oordelen?

Slechts drie van de respondenten gingen eerst kort in op het meningsverschil tussen de ouders en losten dat snel op: die moeten onderling gewoon even overleggen om tot een akkoord te komen. Niemand meldde dat de vader als priesterschapsdrager enige voorrang zou krijgen. Ook bij andere vragen over partnerrelaties maakten gehuwde respondenten duidelijk dat de Proclamatie, die de vader een presiderende rol toekent, bij hen niet gold. Sigrid: 'Presideren betekent dat papa en mama overleggen en dat papa dan mag zeggen waar mama hem van overtuigd heeft.' De eigenlijke aandacht bij deze vignette ging dus meteen naar het dilemma van het al dan niet naar het feestje gaan, waar vooral de moeders onder de respondenten de ambivalentie vanuit eigen ervaringen herkenden. Volgende argumenten en strategieën kwamen aan bod om de SA op te lossen.

\section{Het feestje meteen als aanvaardbaar bepalen}

De meer liberale leden hadden geen moeite om de ambivalentie te bezweren. Renée: 'Ik vind een verjaardagsfeestje geen breken van de sabbat. Dat is gezellig zijn, dat is samen zijn, dat is verbinding, dus voor mij mag ze gaan.' 
Enkelen erkenden wel dat anderen er anders over zouden denken. Saskia: 'Is dat nu een dilemma? Voor sommige mensen wel, denk ik. Ik zou daar geen problemen mee hebben om mijn dochter naar een verjaardagsfeestje te sturen op zondag.' Ook Lisette:

Oh, die zou naar dat feestje mogen. Ik zou dat absoluut geen probleem vinden, want als je al 's morgens naar de kerk gaat en het is in de namiddag een feestje, ik vind dat moet kunnen. Verbieden? Ik hou niet van fanatieke mensen. Fanatiek zijn, dat is zonder liefde.

\section{Met een goede kant compenseren}

Anna besefte dat het dochtertje zelf in gewetensnood kon komen en blikte terug op eigen ervaring toen haar kinderen nog jong waren:

Wij zegden dan: 'Ja, wijzelf zouden geen feestje geven op zondag, maar dat kindje verjaart, en dat kindje wil graag dat je komt, en je steunt dat kindje. En dus mag je naar dat feestje omdat je dat kindje steunt.' Zo deden wij dat met onze kinderen.

Anna verbreedde het beeld ook naar 's zondags op restaurant gaan met nietmormoonse familie buiten het eigen gezin (veel mormoonse gezinnen buiten de Mormon Culture Region hebben immers verwanten die geen lid van de kerk zijn):

Je doet slechter door te zeggen 'nee, wij doen dat niet op zondag'. Door deel te nemen laat je zien aan je familie dat je om hen geeft, ik vind dat dat primeert. Ik heb dan het gevoel dat Hemelse Vader zou zeggen 'ik ben blij dat je samen zit en dat je mekaar de tijd en vriendschap geeft.'

Ook Stella, die het kind naar het feestje laat gaan 'voor het welzijn van het kind' en de nood aan 'sociale netwerken', heeft een compenserende strategie voor het conflict: 'Ik zou dat misschien oplossen, door als ouders naar die andere ouders te bellen en te vragen "kunnen we je komen helpen?", dan kan je er dienstbetoon van maken. Ik denk dat er wel creatieve oplossingen zijn om die twee kanten hier te verzoenen.'

\section{Gevolgen afwegen}

Didi: 'Ik vind wel dat je het moet toelaten. Want als je ze te veel van die dingen afhoudt, dan maken ze geen vrienden en dan gaan ze hoe langer hoe meer van de kerk weg. Naar een vriendje haar feestje gaan, ik vind dat dat moet 
kunnen. Want anders gaan ze zelf revolteren en wegblijven.' Dat is ook de mening van Irma:

Weet je, je moet ook een beetje balanceren met wat je kinderen willen. Als je ze helemaal wereldvreemd gaat maken, ik niet. Je moet een klein beetje kunnen schipperen. De kerk in het midden houden. We zijn in de wereld maar niet van de wereld, maar blijf een beetje normaal. Of anders jaag je ook je kinderen weg.

De meer conservatieve leden getuigden van meer gewetensnood. Vera dacht er eerst aan om de keuze af te wentelen op het kind, maar besefte het problematische ervan (eigenlijk al SA voor een kind). Ze geeft dus toe, maar met toch nog een vermaning naar het kind toe:

Dit feest, het is inderdaad belangrijk voor het kind omdat het al integratieproblemen heeft, en een verjaardagsfeestje vind ik niet zo erg. Maar ik zal wel wijzen op het probleem. Mijn eerste gedachte, 'we zouden het kind zelf de keuze kunnen laten maken', maar 9 jaar is jong. In dit geval, ik zou ze wel laten gaan, maar wel eerst zeggen 'eigenlijk doen we dat niet, maar in dit geval ...'

\section{Zichzelf vanuit ervaring wijzer en toleranter zien}

Verschillende respondenten erkenden geëvolueerd te zijn. Judith:

Als je mij die vraag 30 jaar geleden had gesteld, dan had ik het niet toegestaan, wel met pijn in het hart, want je hebt een kind dat anders nooit ergens terecht kan. Maar nu vandaag, na zoveel jaren lidmaatschap, ik denk niet dat ze door dat verjaardagsfeestje de sabbat overtreedt. Dit is bij vriendjes van 9 jaar. We kunnen haar niet in een dwangbuis duwen, laat haar dat moment met haar vrienden, het zal haar misschien meer deugd doen dan de zondag hier gewoon bij ons te zitten en op haar eentje te jammeren want de andere vriendjes hebben een feestje. En dan komt ze maandag op school. Ik weet het niet, maar ik zou ze liever laten gaan.

Sigrid vertelde dat ze uit 'een heel streng mormoons milieu' komt, 'geen feestjes op zondag' en voor het overige draaide heel haar jeugd om de kerk. Daardoor was ze volgens haar ook 'niet populair' op school. Nu ze vanop middelbare leeftijd terugblikt:

Mijn kinderen zijn altijd op zondag naar feestjes kunnen gaan. En ik weet dat er mensen in de kerk zijn die daar dan schande over spreken, want dat mag niet. Maar ik ben door met mijn man getrouwd te zijn steeds liberaler geworden, 
want mijn schoonzus heeft een heel groot huis met een zwembad, en op zondag familiefeest en dan al die kinderen in het zwembad. Maar zondagmiddag mag je eigenlijk niet zwemmen. Maar ik zeg 'waar doen we eigenlijk moeilijk over?’ De familie is bij elkaar, moeten wij nu allemaal op een stoeltje gaan zitten en wachten tot die zondag voorbij is? Dat is die puriteinse kokervisie. Ik zeg 'jongens, gebruik nu toch even je gezond verstand. Wat wil je bewerkstelligen, wat is het doel, wat wil je verhinderen, waar wil je komen?’

\section{Besluit}

In haar studie van de relaties tussen familie en religie noteerde Bulanda (2011) dat klassieke benaderingen die dergelijke relaties beschrijven de complexiteit van de individuele reacties en interpretaties onvoldoende in kaart brengen. Aandacht voor SA, daarentegen, reveleert 'far more variability, inconsistency, and agentic action in these relationships (and sometimes a complete lack of a relationship) than what traditional, simplistic models of the religion-family connection suggest' (Bulanda 2011, 182).

Hetzelfde geldt voor de ongenuanceerde voorstelling van de positie van vrouwen in conservatieve religies. Veralgemeningen leiden tot stereotypen waarbij vaak het beeld van vrijheidsbeperking van de vrouw primeert, terwijl de individuele persoonlijkheden en eigen keuzes niet erkend worden. Zo meldt het Belgische Informatie- en Adviescentrum inzake de Schadelijke Sektarische Organisaties, deel van het Ministerie van Justitie, over de positie van de vrouw in het mormonisme, zonder verdere uitleg: 'De houding ten aanzien van de vrouw ligt niet in de lijn van de Europese en internationale trend tot gelijkheid van man en vrouw' (IACSSO 2003). In een brochure die het Centrum over het mormonisme ter beschikking stelt, wordt 'de rol van de vrouw' als volgt omschreven, ook zonder verdere uitleg: 'Alhoewel haar werkterrein kan worden uitgebreid tot "sociale" taken, bestaat het ideaal erin kinderen groot te brengen en op te voeden. De vrouw is onderworpen aan haar man (die van zijn kant uitgenodigd wordt tot zin voor maat), die ze nodig heeft om toegang te hebben tot de eeuwigheid. Buitenshuis werken zou gevaarlijk zijn voor haar trouw aan het onderricht en aan de moraal' (IACSSO 2002).

Zelfs indien in mormoonse publicaties aanwijzingen voor dergelijke voorstelling gevonden kunnen worden, reveleert onderzoek naar de werkelijke beleving van mormoonse vrouwen een ander beeld. Onze respondenten zijn geen willoze, binnenshuis gehouden pionnen in een door mannen beheerste wereld. Wanneer zij geconfronteerd worden met tegenstrijdige normen die 
voor SA zorgen, dan blijkt dat zij hun genderrollen zelf beheren en hun relatie met de kerk, de maatschappij en het gezin zelf bepalen. Om SA op te lossen gebruiken zij daartoe argumenten en strategieën die zij in de structuren zelf van kerk, maatschappij of gezin vinden. Zij wegen gevolgen af en kiezen de weg in hun voordeel. Ze rationaliseren de draagwijdte van richtlijnen zodat die voor hen niet toepasselijk zijn. Ze beroepen zich op elementen in de religie zelf, zoals persoonlijke openbaring, Gods welwillendheid en de eeuwige toekomst, om discrepanties te ontwijken. Ze compenseren een overtreding met een goede daad. Ze weten het ook te waarderen wanneer ze bij ongelijke gender-behandeling, zoals bij het exclusief mannelijk priesterschap, baat hebben. Dit alles betekent niet dat er geen frustraties zijn, maar waar het nog hapert vinden ze manieren om er zich tijdelijk mee te verzoenen of om hun impact behendig te verhogen. Tegelijkertijd vertonen ze veel interne variaties in de keuze van argumenten en strategieën.

Geen van de respondenten in ons onderzoek nam een fundamentalistische houding aan. Ze gaven aan goed te functioneren in de maatschappij, waar ze hun opleiding hadden genoten en professioneel konden functioneren. Allen sloten zich aan bij West-Europese normen met betrekking tot huwelijksleeftijd, timing en aantal kinderen, opleiding en tewerkstelling. Opvallend was ook de sterke identiteitsbevestiging van elke respondent. Standpunten werden verwoord als ik-statements. Bij elke vraag en in elke situatie bevestigden onze respondenten hun eigen visie, inzichten en vrije wil. Geen enkele respondent verschool zich achter simpele gezagsargumenten.

Deze nuanceringen gelden trouwens evengoed voor vrouwen in Utah. Ook al stemmen ze volgens surveys overwegend Republikeins, ook al hangen ze openlijk 'Christian right' principes aan en vertonen ze een uiterlijke conformiteit om in het mormoons bepaalde maatschappelijk stramien te passen, dan weten we nog niets over hun individuele gevoelens en handelingen. Uit kwalitatief onderzoek zoals het onze blijken velen van hen, in Utah maar ook elders, structurele ambivalenties in hun dagelijks leven te ervaren en lossen zij die op hun eigen manier op (Leamaster \& Bautista 2018; Halford 2020; Nzojibwami 2009). Een veralgemeend beeld van 'de mormoonse vrouw' is dus niet mogelijk, waar ook ter wereld.

Bij vrouwen in conservatieve religies zijn de erkenning van ambivalentie en de bereidheid oplossingen te vinden belangrijke attitudes om flexibel te kunnen functioneren. Ambivalentie niet onder ogen willen zien typeert fundamentalisme. Onderzoek naar SA hoopt aldus relevant te zijn voor gelijkaardige studies van religieuze minderheden waarbij dieper wordt ingegaan op individuele situaties in interactie met omliggende structuren. Het blootleggen 
van argumenten en strategieën die SA helpen reduceren kan dan mogelijk dienstbaar zijn in het helpen ontmantelen van schadelijk fundamentalisme.

\section{Noot}

1 In de Engelstalige literatuur zowel 'structured' als 'structural ambivalence' genoemd, maar sommigen maken een onderscheid tussen beide.

\section{Literatuur}

Avishai, O. (2008),

'Doing Religion' in a Secular World: Women in Conservative Religions and the Question of Agency, in: Gender a Society, 22 (4), 409-433.

Avishai, O. (2016),

Gender, in: Yamane, D. (ed.), Handbook of Religion and Society, Dordrecht: Springer, 373-394.

Bean, L., \& B.C. Martinez (2014),

Evangelical Ambivalence toward Gays and Lesbians, in: Sociology of Religion, 75 (3), 395-417.

Beek, W.E. van (2005),

Mormon Europeans or European Mormons? An 'Afro-European' View on Religious

Colonization, in: Dialogue: A Journal of Mormon Thought, 38 (4), 3-36.

Beek, W.E. van, E. Decoo \& W. Decoo (2020),

Persisting in a Secular Environment: Mormonism in the Low Countries, in: Shepherd, R.G., A.G. Shepherd \& R.T. Cragun (eds.), The Palgrave Handbook of Global Mormonism, Cham: Palgrave Macmillan, 503-531.

Bulanda, J. R. (2011),

Doing Family, Doing Gender, Doing Religion: Structured Ambivalence and the Religion-Family Connection, in: Journal of Family Theory \& Review, 3 (3), 179-197.

Burchardt, M., M. Griera \& G. García-Romeral (2015),

Narrating Liberal Rights and Culture: Muslim Face Veiling, Urban Coexistence and Contention in Spain, in: Journal of Ethnic and Migration Studies, 41 (7), 1068-1087.

Burke, K.C. (2012),

Women's Agency in Gender-Traditional Religions: A Review of Four Approaches, in:

Sociology Compass, 6 (2), 122-133.

Connidis, I.A., \& J.A. McMullin (2002),

Sociological Ambivalence and Family Ties: A Critical Perspective, in: Journal of Marriage and Family, 64 (3), 558-567. 
Davidson, L. (2021, January 17),

Latter-day Saints are Overrepresented in Utah's Legislature, Holding 9 of Every 10 Seats, in: Salt Lake Tribune, A5-A6.

Decoo, E. (2021),

Mormon, Flemish, and Female: A Qualitative Study of the Perception of Gender Roles among Mormon Women in Flanders. PhD diss., Gent: Universiteit Gent.

Decoo, W. \& E. Decoo (2019),

De visie op homoseksualiteit bij mormonen: verkenning in een historisch-sociologisch kader, in: Religie a Samenleving, 14 (3), 244-271.

Decoo-Vanwelkenhuysen, C. (2016),

Mormon Women in Europe: A Look at Gender Norms, in: Holbrook, K., \& M. Bowman (eds.), Women and Mormonism: Historical and Contemporary Perspectives, Salt Lake City, UT: University of Utah Press, 213-229.

Finkelman, Y. (2014),

The Ambivalent Haredi Jew, in: Israel Studies, 19 (2), 264-293.

Gooren, H. (2010),

Religious Conversion and Disaffliation: Tracing Patterns of Change in Faith Practices, New York: Palgrave Macmillan.

Halford, A. (2020),

Women's Gender Roles and Mormonism in England, in: Petrey, T.G. \& A. Hoyt (eds.), The Routledge Handbook of Mormonism and Gender, New York: Routledge, 392-404.

Heaton, T.B. \& C.K. Jacobson (2015),

The Social Composition of Mormonism, in: Givens, T. \& P. Barlow (eds.), The Oxford Handbook of Mormonism, Oxford: Oxford University Press, 309-333.

IACSSO (2002),

Informatie over de Kerk van Jezus Christus van de Heiligen der Laatste Dagen (Mormonen), Brussel: IACSSO.

IACSSO (2003),

Tweejaarlijks verslag (jaar 2001-2002), Brussel: IACSSO.

Jacobs, B. (2020),

Utah Ranked Worst State for Women's Equality Three Years in a Row, in: Salt Lake Tribune, (2020, August 25), A1, A4.

Järvinen, M. \& S.T. Luckow (2020),

Sociological Ambivalence: Relationships between Birth Parents and Foster Parents, in: Sociology, 54 (4). doi:10.1177/0038038519896937.

Khan, S. (2002),

Aversion and Desire: Negotiating Muslim Female Identity in the Diaspora, Toronto: Canadian Scholars' Press. 
Kopelowitz, E. (2001),

Religious Politics and Israel's Ethnic Democracy, in: Israel Studies, 6 (3), 166-19o.

Leamaster, R. \& A. Bautista (2018),

Understanding Compliance in Patriarchal Religions: Mormon Women and the Latter Day Saints Church as a Case Study, in: Religions, 9 (5), 1-18.

Lipka, M. (2013),

Big Majority of Mormons (Including Women) Oppose Women in Priesthood, in: Pew Research Center, (2013, October 8).

Merton, R.K. \& E. Barber (1963),

Sociological ambivalence, in: Tiryakian, E.A. (ed.), Sociological Theory: Values and Sociocultural Change, New York: Free Press of Glencoe, 90-120.

Monson, T.H. (2011),

Priesthood Power, in: The Ensign of the Church of Jesus Christ of Latter-day Saints, 41 (5), 66-69.

Nieuwkerk, K. van (2014),

Conversion to Islam and the Construction of a Pious Self, in: Rambo, L.R. \& C.E. Farhadian (eds.), The Oxford Handbook of Religious Conversion, New York, NY: Oxford University Press, 668-686.

Nzojibwami, V. (2009),

Creating Space: How Mormon Women Reconcile Their Feminist Attitudes within a Patriarchal Religion, Master's thesis, Calgary: University of Calgary.

Oaks, D.H. (2018),

Parents and Children, in: The Ensign of the Church of Jesus Christ of Latter-day Saints, 48 (11), 61.

Pew Research Center (2014),

Religious Landscape Study: Mormons.

https://www.pewforum.org/religious-landscape-study/religious-tradition/mormon/ Phillips, R. \& R.T. Cragun (2011),

Mormons in the United States 1990-2008: Socio-demographic Trends and Regional Differences, Hartford, CT: Trinity College.

Riess, J. (2019),

The Next Mormons: How Millennials Are Changing the LDS Church, New York: Oxford University Press.

Robins, R. (2011),

The Male Educational Leader in Utah: Gender Dynamics, Power, and Relational Leadership in a Mormon Dominant Culture. PhD diss., Las Vegas, NV: University of Nevada. 
Steele, S.M. \& A.S. Helmuth (2019),

Predicting Ambivalence: When Same-Sex Sex is Only 'Sometimes Wrong', in: Journal of Homosexuality, 66 (3), 421-442.

Uecker, J.E. (2014),

Religion and Early Marriage in the United States: Evidence from the Add Health Study, in: Journal for the Scientific Study of Religion, 53 (2), 392-415. 